\title{
Safety Evaluation of Seal Oil and its Lipid-Lowering Effect on
}

\section{Hypercholesterolemia Rats}

\author{
Litao Yang, Yinlu Liu, Cuicui Bi, Yu Guo, Jian Zhao, Bo Zhang* \\ College of Biochemical Engineering, Beijing Key Laboratory of Bioactive Substances and Functional Foods, Beijing \\ Union University; No.197 Beitucheng West Road, Huayuan Street, Haidian District,Beijing100191, China \\ *Corresponding Author: Bo Zhang, College of Biochemical Engineering, Beijing Key Laboratory of \\ Bioactive Substances and Functional Foods, Beijing Union University; No.197 Beitucheng West Road, \\ Huayuan Street, Haidian District, Beijing100191, China
}

\begin{abstract}
To study the toxicity of seal oil and its lipid-lowering effect on hypercholesterolemia, acute toxicity study, sub-acute toxicity study, genotoxicity studies and lipid-lowering test were done on mice or rats. The acute oral study was carried out in male and female Kunming mice. They took $19 \mathrm{mg} / \mathrm{kg} \mathrm{BW}$ of seal oil orally for 14 days and observed and recorded. In the subacute oral toxicity study, rats were administered with three doses $(0.83,1.67,3.33 \mathrm{~g} / \mathrm{kg} \mathrm{BW})$ by orally for 28 days. In genotoxicity studies, the genetic toxicity of Seal oil was tested through Ames test, in vivo mouse bone marrow micronucleus test and spermatocyte chromosomal aberration test. Safety of Seal oil was evaluated by acute oral toxicity study, subacute oral toxicity study and genotoxicity studies. Seal oil was not mutagenic and did not induce other chromosomal events. Additionally, seal oil was not genotoxic in Ames test, nor did it induce micronucleus of mouse bone marrow and chromosome aberration of spermatocytes in vivo test at the dose of $3.80 \mathrm{~g} / \mathrm{kg}$ BW. In the study of hypercholesterolemia rats, each dose of seal oil significantly reduced the cholesterol and triglycerides of hypercholesterolemia rats $(P<0.01)$. Based on the results of the in vitro and in vivo studies, seal oil at a dose of $19.00 \mathrm{~g} / \mathrm{kg} \mathrm{BW}$ did not show acute toxicity, and seal oil did not show sub-acute toxicity and genotoxicity. Seal oil can also reduce total cholesterol and triglyceride in hypercholesterolemia rats, which has a good lipid-lowering effect.
\end{abstract}

Keywords: safety; seal oil; acute oral toxicity study; subacute oral toxicity study; genotoxicity studies; hypercholesterolemia

\section{INTRODUCTION}

Seal oil is a natural marine biological product extracted from the fat of seal. It is more easily absorbed by the human body than fish oil $(1,2)$. Differences in the fatty acid composition and positional distribution of $\omega-3$ polyunsaturated fatty acids ( $\omega$-3PUFA) in triglycerides of fish-oil and seal-oil are suggested to trigger metabolic differences(3). Seal oil is non-concentrated and non-polluting and considered an ideal source of $\omega$-3PUFA. Seal oil is a kind of pure natural food, in which the content of $\omega$-3PUFA is as high as $25 \%(4)$, which is the highest content in animals in nature. Seal oil has a wide range of pharmacological effects, and the effect of enhancing immune function is definite. Its application in the field of health products is a major development trend.

The research on seal oil originated from the epidemiological study of the Eskimos with a very low 
incidence of cardiovascular disease. This effect is derived from the $\omega$-3PUFA in seal oil. Studies have found that dietary $\omega$-3PUFA increase in proportion to inhibit fat accumulation(5) and mainly include $\alpha$-linolenic acid (ALA), docosahexaenoic acid (DHA) and eicosapentaenoic acid (EPA), which are necessary for the human body but cannot be synthesized by itself(6) and have different functions(7). An unsaturated fatty acid must be ingested from food. $\omega$-3PUFA have a variety of biological activities. It can effectively promote the growth and development of the human body, have the prevention and treatment of diabetes, cardiovascular and cerebrovascular diseases, anti-cancer, lipid-lowering and nervous system diseases aspect and other important physiological functions(8-11). At the same time, it also effectively reduces the incidence of non-alcoholic fatty liver. More and more evidences showed that seal oil promotes fatty acid oxidation and inhibits inflammation by inhibiting the formation of fat(12). Seal oil was used as a source of $\omega$-3PUFA in Canada but prohibited in the United States and European Union. Although Broadwater et al. analyzed the composition of seal oil and fish oil by two reliable lipid profiling methods(13), now there are relatively few evaluations of the safety of seal oil in vivo. We should be very cautious for the application of this product in food.

High cholesterol is a common symptom of the general population. It is defined as an increase in fasting serum cholesterol(14). At the same time, cholesterol is an important structural component of plasma membrane and myelin, which maintains the physiological functions of neurons(15). Excessive cholesterol will increase the risk of cerebrovascular disease, and it can reduce the probability of cerebrovascular disease, if that disease was treated earlier. However, current lipid-lowering drugs have obvious side effects on liver and kidney damage, striated muscle and gastrointestinal reactions(16). Seal oil is a good natural diet for lowering cholesterol and makes full use of the functions of this food to prevent or improve hypercholesterolemia and complications has become a research trend today(17).

In order to further studying the safety of seal oil for long-term consumption and its lipid-lowering function, we carried out two tests on seal oil: the first test was about the acute oral toxicity study, subacute oral toxicity study and genotoxicity studies of seal oil; the second test is about through the establishment of hypercholesterolemia rat model studies the lipid-lowering function of seal oil.

\section{MATERIALS AND METHODS}

\subsection{Materials}

The light yellow oily liquid seal oil sample were produced and provided by Wuxianji (China) Co., Ltd. (contains $99.5 \%$ seal oil and $0.5 \%$ vitamin E). The refined seal oil was processed through the process of degumming, deacidification, decolorization, and deodorization. Then seal oil was added an appropriate amount of vitamin $\mathrm{E}$ as an antioxidant and stored for studying.

\subsection{Animals and Feed}

For the acute oral toxicity study and genotoxicity studies, Kunming mice (SPF) were selected as experimental animals raised by BEIJING HFK BIOSCIENCE Co., LTD. For the subacute oral toxicity study, SD rats were selected as experimental animals raised by BEIJING HFK BIOSCIENCE Co., LTD. All dose groups in the above test were given normal feed. For the hypercholesterolemia rats study, SD rats were selected as experimental animals raised by BEIJING HFK BIOSCIENCE Co., LTD. High cholesterol feed ( $1.2 \%$ cholesterol, $0.2 \%$ sodium cholate, $4.5 \%$ lard and appropriate amount of casein, calcium hydrogen phosphate, stone powder) and normal feed (maintenance feed) were selected by BEIJING HFK BIOSCIENCE Co., LTD. The trial protocols were reviewed by the Animal Ethics Committee of Beijing Union University (Nos.201801). 


\subsection{Acute Oral Toxicity Study}

The study followed OECD guideline 425 for acute toxicity testing(18). Twenty Kunming mice of $18 \mathrm{~g} \sim 22 \mathrm{~g}$ were selected, half male and half female. After adapting to feeding and observing no abnormal condition, the experiment was carried out. During the experiment, the animals were freely access to drink and eat. The sample was used for direct gavage. The maximum gavage capacity of mice is $20 \mathrm{ml} / \mathrm{kg} \mathrm{BW}$, and now the gavage dose was $19.00 \mathrm{~g} / \mathrm{kg} \mathrm{BW}$ in this study. The mice were fasted for $2 \mathrm{~h}$ after the last gavage. Observe continuously for 14 days, observe and record the general state of the animal, signs of poisoning, and death. Afterward, the mice were euthanized with an overdose of anesthetic.

\subsection{Subacute Oral Toxicity Study}

Subacute oral toxicity was achieved according to OECD guidelines 407 with minor modifications (19). There were eighty rats, half male and half female. After adapting to feeding and observing no abnormal condition, they were randomly divided into 4 groups with each 20 rats, as the control group, low, medium and high does groups $(0.83,1.67,3.33 \mathrm{~g} / \mathrm{kg} \mathrm{BW})$. The rats were on gavage once time every day. Raised in a single cage, observed and recorded the general performance of the animals every day. Rats were weighed every week. After fasting for 16 hours on the 28th day, the fasting body weight was weighed, blood was taken, and biochemical analysis was performed after centrifugation. After the rats were killed, carry out the following index examination. Hematology index determination using an automatic analyzer (Hitachi 7170, Japan): determination of red blood cell count (RBC), hemoglobin (HB), white blood cell count (WBC), platelet count (PCT), hematocrit level (HTC). Determination of blood biochemical indicators: aspartate transaminase (AST), alanine transaminase (ALT), blood urea nitrogen (BUN), serum creatinine (SCR), glucose (GLU), total cholesterol (TC), total triglycerides (TG). Organ weighing: the absolute weight of the heart, liver, kidney, testis, ovary and calculate the organ coefficients (organ coefficients $(\%)=$ organ/body $(\%)$ ). Histopathological analysis: for histopathological examination, liver was fixed in $10 \%$ neutral buffered formalin for one week, embedded in paraffin, and sliced into 5- $\mu \mathrm{m}$ sections. Sections were then stained with haematoxylin and eosin (H\&E).

\subsection{Genotoxicity Studies}

\subsubsection{Ames Test}

The mutagenic potential of the seal oil was evaluated in Ames test with minor modifications according to OECD guidelines 471(20). The tester strains of histidine deficient Salmonella typhimurium TA97, TA98, TA100, TA102 and TA1535 were selected to carry out the standard plate incorporation test in the presence and absence of the metabolism activation system (S9 system). Two

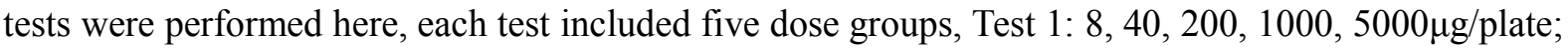
Test 2: $50,158,500,1580,5000 \mu \mathrm{g} /$ plate with grew aseptically. Positive, solvent 1 (sterile water), solvent 2 (DMSO) and untreated were set up at the same time. The positive was dixone $(50 \mu \mathrm{g} / \mathrm{plate}$, applicable strains TA97, TA98, TA102), sodium azide $(1.5 \mu \mathrm{g} /$ plate, applicable strains TA100, TA1535) without $\mathrm{S} 9$ and the positive was 2 -aminofluorene $(10 \mu \mathrm{g} / \mathrm{plate}$, suitable for strains TA97, TA98, TA100), 1,8-dihydroxy-anthraquinone $(50 \mu \mathrm{g} / \mathrm{plate}$, suitable for strains TA102); and cyclophosphamide $(200 \mu \mathrm{g} /$ plate, suitable for strains TA1535) with S9.

In the test, $0.1 \mathrm{ml}$ of test strain enrichment solution, $0.1 \mathrm{ml}$ of test substance solution and $0.5 \mathrm{ml}$ of S9 mixed solution (when metabolic activation is required) were added to the top agar, mix well, and pour into the bottom medium plate, 3 per dose flatware. Incubated at $37 \pm 1^{\circ} \mathrm{C}$ for $48 \mathrm{~h}$, and counted the 
number of colonies changed per dish.

\subsubsection{In Vivo Mouse Bone Marrow Micronucleus Test}

Fifty healthy mice weighing $25 \mathrm{~g}$ to $30 \mathrm{~g}$ were selected. After adaptation and observation, there were no abnormalities and randomly divided into 5 groups, with 10 mice in each group (half male and half female). Take cyclophosphamide (40 mg/kg BW) as a positive control, corn oil as a solvent control. The low, medium and high dose groups were $0.95,1.90,3.80 \mathrm{~g} / \mathrm{kg} \mathrm{BW}$. Mice were treated by oral gavage $(4 \mathrm{ml} / \mathrm{kg} \mathrm{BW})$. Adopt $30 \mathrm{~h}$ administration method and the mice were given the simple by gavage twice, the time interval was $24 \mathrm{~h}$. After $6 \mathrm{~h}$, they were killed by cervical dislocation in the last gavage. Took sternal bone marrow and diluted smear with bovine serum, fixed with methanol and Giemsa staining. Under an optical microscope, each animal counted 2000 polychromatic erythrocytes (PCEs) and calculated the micronucleus cell rate. At the same time, each animal counted 200 red blood cells and counted the proportion of polychromatic red blood cells in total red blood cells.

\subsubsection{Spermatocyte Chromosomal Aberration Test In Mice}

Twenty-five sexually mature male mice were randomly divided into 5 groups after adaptive feeding and observation. Cyclophosphamide (40 mg/kg BW) was used as positive control and corn oil as solvent control. The three dose groups of low, medium and high were $0.95,1.90$ and $3.80 \mathrm{~g} / \mathrm{kg} \mathrm{BW}$. The sample group and the solvent group were given by oral gavage once a day for 5 days. The positive group was injected intraperitoneally with cyclophosphamide. In each group, the mice were killed (colchicine was injected intraperitoneally 5 hours before the animals were sacrificed.) and sampled on the 14th day after the first administration of seal oil. The mice were sacrificed by cervical dislocation. Spermatocytes were taken from testicles for section staining. Non overlapping sperm cell $(\mathrm{n}=1000)$ were observed for each mouse and included fragments, micro chromosomes, and translocations, and analyzed under a Nikon biological microscope. Spermatocyte malformation rate (\%) was calculated.

\subsection{Seal Oil Lipid-Lowering in Hypercholesterolemia Rats Study}

The rats were randomly divided into 2 groups. The twelve rats were given maintenance feed as a control group (Control), and forty-eight rats were given high cholesterol feed as a test group. After 2 weeks of modeling, blood was collected and the serum was separated by centrifugation, and the serum TC and TG were determined. After successful modeling, forty-eight hypercholesterolemia rats with high cholesterol feed were randomly divided into 4 groups: model group (Model, $n=12$ ), low-dose group (L, $n=12)$, medium-dose group $(M, n=12)$ and high-dose group $(H, n=12)$. From the third week, corn oil was used as a solvent to prepare different doses of seal oil. The L, M and $\mathrm{H}$ were given high cholesterol feed with different doses of seal oil $(0.17,0.33$ and $0.67 \mathrm{~g} / \mathrm{kg} \mathrm{BW})$. The Model was given high cholesterol feed and was given a gavage with corresponding volume of solvent corn oil, while the Control was given the maintenance feed and was given a gavage with corresponding volume of solvent corn oil for 4 weeks. After the 6th week, the body weight was measured. Blood was collected, the serum was separated by centrifugation, and the serum TC and TG were determined. The rats were sacrificed.

\subsection{Statistical Analysis}

Statistical analysis was performed using SPSS 12.0. All data are expressed as mean \pm standard deviation. Statistics uses one-way analysis of variance. The data from the in vivo mouse micronucleus assay were analyzed using Chi-square distribution. Data from the mouse sperm abnormality assay were processed using the Wilcoxon rank sum test. 


\section{RESULTS}

\subsection{Acute Oral Toxicity Study}

Toxicological research helps make important decisions about new chemical entities as clinically effective and safe drugs. During the study period, the appearance and behavior of the animals in all animal groups were similar. During the 14 days of the experimental period, the animal was in normal state, with no signs of poisoning or death. The approximate acute lethal dose (LD50) of seal oil was greater than $19.0 \mathrm{~g} / \mathrm{kg} \mathrm{BW}$ for both female and male mice, which is not toxic.

\subsection{Subacute Oral Toxicity Study}

\subsubsection{Body Weight}

During the experiment, no abnormal behavior of the rats was recorded. It can be seen from Figure 1. The weight of rats was measured every seven days, and it was found that the weight increased during the treatment period. However, the weight of measured rats were compared with the control group at the same time, difference of each dose group wasn't significant $(\mathrm{P}>0.05)$.
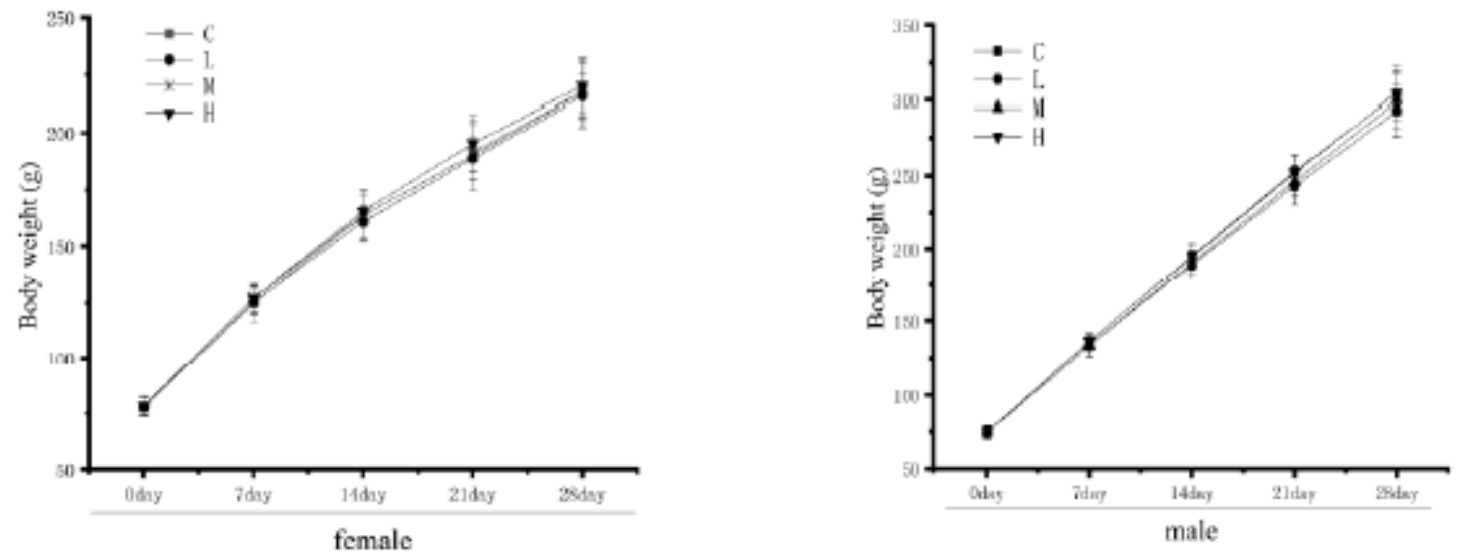

Figure 1. Effect of body weight of rats treated with seal oil

\subsubsection{Hematologic and Biochemical Parameters}

Introduced by Table 1, compared with the control group, each dose group has no significant difference on hematological of rats $(P>0.05)$. Showed by Figure 2, compared with the $\mathrm{C}$, the serum liver function indexes and renal function indexes of each dose group were not significantly $\operatorname{different}(P>0.05)$, and there was no statistical significance.

A

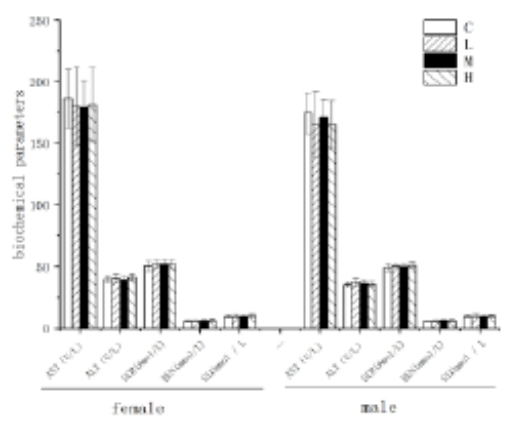

$\mathrm{B}$

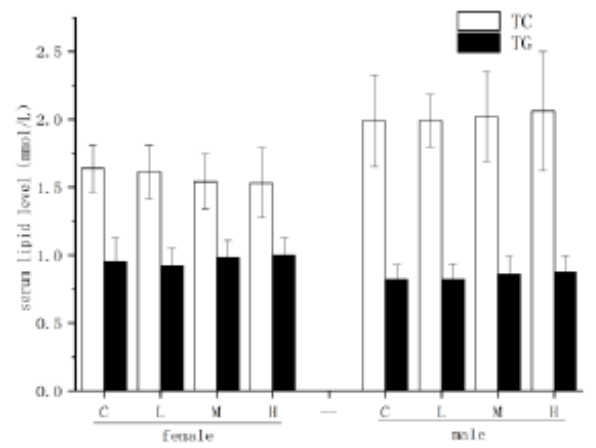

Figure 2. Effect of seal oil oral administration on biochemical parameters in rats: A: liver and kidney indicators in biochemical parameters, B: serum lipid level in biochemical parameters. 
Safety Evaluation of Seal Oil and its Lipid-Lowering Effect on Hypercholesterolemia Rats

Table1. Effect of seal oil oral gavage on hematological parameters in rats.

\begin{tabular}{|c|c|c|c|c|c|c|c|c|}
\hline \multirow{2}{*}{ Parameter } & \multicolumn{4}{|c|}{ group (female) } & \multicolumn{4}{|c|}{ group (male) } \\
\hline & $\mathrm{C}$ & $\mathrm{L}$ & $\mathrm{M}$ & $\mathrm{H}$ & $\mathrm{C}$ & $\mathrm{L}$ & M & $\mathrm{H}$ \\
\hline $\operatorname{RBS}\left(10^{12} / \mathrm{L}\right)$ & $7.87 \pm 0.43$ & $7.96 \pm 0.50$ & $7.92 \pm 0.34$ & $7.64 \pm 0.39$ & $7.82 \pm 0.19$ & $7.66 \pm 0.54$ & $7.75 \pm 0.27$ & $7.91 \pm 0.29$ \\
\hline $\mathrm{HB}(\mathrm{g} / \mathrm{L})$ & $162 \pm 7$ & $165 \pm 5$ & $167 \pm 5$ & $164 \pm 6$ & $167 \pm 5$ & $165 \pm 5$ & $167 \pm 6$ & $169 \pm 8$ \\
\hline $\mathrm{WBC}\left(10^{9} / \mathrm{L}\right)$ & $5.5 \pm 2.2$ & $5.3 \pm 1.5$ & $6.1 \pm 1.6$ & $6.8 \pm 2.2$ & $7.0 \pm 1.4$ & $7.3 \pm 1.4$ & $7.3 \pm 1.4$ & $6.8 \pm 1.4$ \\
\hline $\operatorname{PLT}\left(10^{9} / \mathrm{L}\right)$ & $1298 \pm 134$ & $1202 \pm 168$ & $1308 \pm 128$ & $1338 \pm 144$ & $1242 \pm 147$ & $1342 \pm 188$ & $1319 \pm 164$ & $1282 \pm 175$ \\
\hline PCT(\%) & $44.6 \pm 1.9$ & $44.6 \pm 2.0$ & $44.5 \pm 1.1$ & $43.5 \pm 1.5$ & $46.6 \pm 1.4$ & $46.0 \pm 1.4$ & $46.4 \pm 1.8$ & $47.6 \pm 2.8$ \\
\hline
\end{tabular}

\subsubsection{Organ Coefficients}

According to the analysis in Figure 3 (A), Compared with the C, the liver organ coefficient of the $\mathrm{L}$ and the $\mathrm{H}$ showed an increasing trend, but the difference was not significant, and there was no statistical significance $(P>0.05)$. As shown in Figure 3 (B), compared with the $\mathrm{C}$ and the $\mathrm{H}$, there was no abnormal change in liver tissue morphology, and the tissue structure was normal by H\&E stain.

(A)

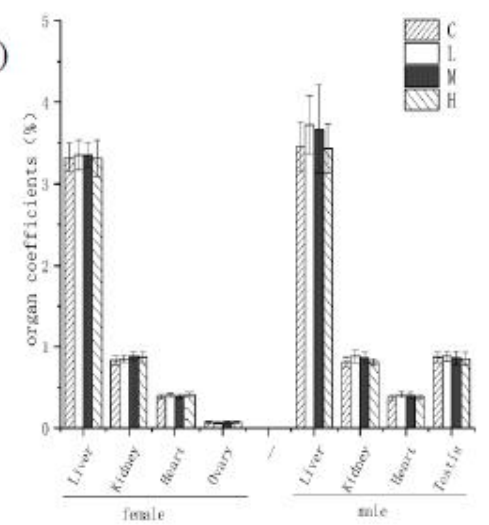

(B)

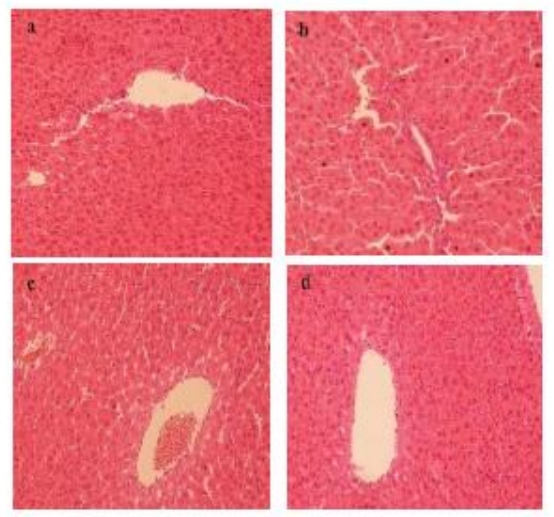

Figure 3. (A): Effect of organ coefficients of rats treated with seal oil in rats. (B): Histopathological examination of liver (H\&E stain, 400×). a (female control group), b (male control group), c (female high-dose seal oil group), d (male high-dose Seal oil group).

\subsection{Genotoxicity Studies}

\subsubsection{Ames Test}

We firstly investigated the mutagenic effect of Seal oil using a bacterial reverse mutation test with five Salmonella typhimurium strains (TA97, TA98, TA100, TA102, and TA1535) with and without S9 system. As shown in Table 2, the number of revertants colonies in the positive group (with or without S9) was more than 2 times higher in the solvent group and the untreated group. It is very significant difference $(P<0.01)$. The number of revertants colonies of seal oil in each dose group didn't exceed that of the solvent group and the untreated group by more than 2 times. There was not dose response relationship and statistical significance among the groups $(P>0.05)$. The confirmatory test showed similar result (Table 3).

Table2. Results of Ames test for seal oil (Test 1)

\begin{tabular}{|l|l|l|l|l|l|}
\hline \multirow{2}{*}{ Treatment } & \multicolumn{5}{l}{ Revertant colonies (CFU) } \\
\cline { 2 - 6 } & TA97 & TA98 & TA100 & TA102 & TA1535 \\
\hline Without S9 metabolic activation & $115.33 \pm 12.66$ & $40.00 \pm 2.00$ & $149.00 \pm 20.30$ & $261.33 \pm 17.04$ & $20.67 \pm 8.39$ \\
\hline Solvent 1 &
\end{tabular}


Safety Evaluation of Seal Oil and its Lipid-Lowering Effect on Hypercholesterolemia Rats

\begin{tabular}{|c|c|c|c|c|c|}
\hline Solvent 2 & $117.33 \pm 11.15$ & $35.33 \pm 3.51$ & $169.00 \pm 22.27$ & $278.00 \pm 13.75$ & $18.67 \pm 3.79$ \\
\hline Untreated & $114.00 \pm 9.17$ & $38.33 \pm 7.23$ & $185.33 \pm 15.95$ & $273.67 \pm 14.29$ & $20.33 \pm 8.08$ \\
\hline \multicolumn{6}{|l|}{ Seal oil $(\mu \mathrm{g} / \mathrm{plate})$} \\
\hline 8 & $122.67 \pm 15.50$ & $33.00 \pm 1.73$ & $163.00 \pm 18.08$ & $273.00 \pm 5.57$ & $19.00 \pm 13.08$ \\
\hline 40 & $111.33 \pm 5.86$ & $41.00 \pm 4.36$ & $136.33 \pm 13.61$ & $279.67 \pm 21.50$ & $26.33 \pm 7.51$ \\
\hline 200 & $126.33 \pm 5.51$ & $41.67 \pm 2.31$ & $159.67 \pm 20.53$ & $268.67 \pm 8.02$ & $18.67 \pm 5.51$ \\
\hline 1000 & $111.33 \pm 10.02$ & $38.00 \pm 5.20$ & $155.67 \pm 35.53$ & $294.67 \pm 5.86$ & $22.33 \pm 4.93$ \\
\hline 5000 & $125.00 \pm 7.21$ & $39.33 \pm 2.52$ & $148.67 \pm 26.31$ & $297.33 \pm 2.89$ & $23.67 \pm 3.06$ \\
\hline Positive control 1 & $1811.00 \pm 174.24^{* *}$ & $836.67 \pm 56.50^{* *}$ & $953.33 \pm 101.04^{* *}$ & $774.00 \pm 73.51^{* *}$ & $500.67 \pm 68.42^{* *}$ \\
\hline \multicolumn{6}{|c|}{ With S9 metabolic activation } \\
\hline Solvent 1 & $118.00 \pm 3.46$ & $36.67 \pm 6.66$ & $161.00 \pm 25.24$ & $278.00 \pm 5.57$ & $27.00 \pm 4.36$ \\
\hline Solvent 2 & $128.33 \pm 6.43$ & $38.00 \pm 6.00$ & $152.33 \pm 25.32$ & $271.67 \pm 19.09$ & $25.67 \pm 7.23$ \\
\hline Untreated & $121.67 \pm 11.24$ & $32.67 \pm 2.08$ & $154.67 \pm 14.19$ & $272.33 \pm 8.50$ & $13.67 \pm 5.51$ \\
\hline \multicolumn{6}{|l|}{ Seal oil $(\mu \mathrm{g} /$ plate $)$} \\
\hline 8 & $117.67 \pm 14.01$ & $31.67 \pm 1.53$ & $145.33 \pm 40.46$ & $279.67 \pm 8.02$ & $19.33 \pm 7.51$ \\
\hline 40 & $114.67 \pm 8.08$ & $38.00 \pm 5.29$ & $175.67 \pm 17.79$ & $280.33 \pm 15.31$ & $22.00 \pm 2.65$ \\
\hline 200 & $114.67 \pm 10.12$ & $34.67 \pm 1.53$ & $170.33 \pm 26.01$ & $266.00 \pm 24.27$ & $19.67 \pm 4.51$ \\
\hline 1000 & $120.00 \pm 11.14$ & $39.00 \pm 4.36$ & $158.00 \pm 21.66$ & $273.67 \pm 10.21$ & $18.33 \pm 7.37$ \\
\hline 5000 & $117.00 \pm 10.15$ & $37.67 \pm 2.08$ & $158.00 \pm 34.64$ & $273.67 \pm 19.14$ & $20.67 \pm 8.50$ \\
\hline Positive control 2 & $1463.00 \pm 54.29^{* *}$ & $2002.00 \pm 97.69^{* *}$ & $939.00 \pm 49.57^{* *}$ & $794.33 \pm 37.02^{* *}$ & $472.00 \pm 61.59^{* *}$ \\
\hline
\end{tabular}

Values are expressed as the means $\pm S D(n=10) .{ }^{*} P<0.05$ Compared with Solvent significant difference, $* * P<0.01$ Compared with Solvent very significant difference

Solvent1: sterile water; Solvent 2: DMSO.

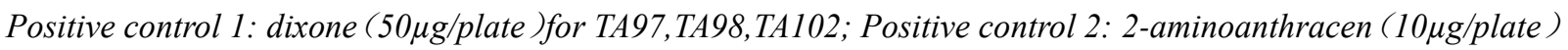

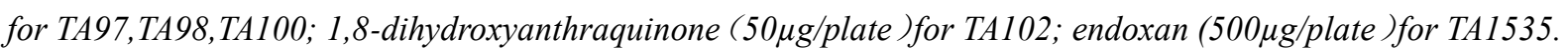

Table3. Results of Ames test for seal oil (Test 2)

\begin{tabular}{|c|c|c|c|c|c|}
\hline \multirow{2}{*}{ Treatment } & \multicolumn{5}{|c|}{ Revertant colonies (CFU) } \\
\hline & TA97 & TA98 & TA100 & TA102 & TA1535 \\
\hline \multicolumn{6}{|c|}{ Without S9 metabolic activation } \\
\hline Solvent 1 & $124.00 \pm 9.54$ & $34.67 \pm 2.08$ & $147.00 \pm 21.93$ & $270.67 \pm 11.06$ & $31.67 \pm 3.21$ \\
\hline Solvent 2 & $113.00 \pm 7.00$ & $35.67 \pm 3.79$ & $161.00 \pm 18.52$ & $274.33 \pm 17.50$ & $28.33 \pm 6.66$ \\
\hline Untreated & $119.33 \pm 15.50$ & $40.00 \pm 3.00$ & $155.00 \pm 26.85$ & $279.67 \pm 15.04$ & $20.33 \pm 11.06$ \\
\hline \multicolumn{6}{|l|}{ Seal oil $(\mu \mathrm{g} /$ plate $)$} \\
\hline 50 & $113.67 \pm 8.14$ & $34.67 \pm 6.35$ & $168.00 \pm 17.69$ & $282.67 \pm 14.05$ & $23.67 \pm 5.51$ \\
\hline 158 & $129.67 \pm 7.64$ & $34.33 \pm 3.21$ & $128.33 \pm 4.73$ & $268.67 \pm 16.26$ & $26.00 \pm 2.65$ \\
\hline 500 & $108.00 \pm 6.08$ & $38.67 \pm 3.51$ & $177.00 \pm 27.40$ & $282.00 \pm 16.64$ & $24.67 \pm 4.93$ \\
\hline 1580 & $124.67 \pm 10.69$ & $36.67 \pm 7.02$ & $160.00 \pm 6.24$ & $287.00 \pm 19.92$ & $25.00 \pm 1.00$ \\
\hline 5000 & $119.00 \pm 7.81$ & $38.00 \pm 1.73$ & $166.67 \pm 24.01$ & $278.67 \pm 15.50$ & $24.67 \pm 6.35$ \\
\hline Positive control 1 & $\begin{array}{l}1931.33 \pm 41.00^{*} \\
*\end{array}$ & $824.67 \pm 61.49^{* *}$ & $896.67 \pm 77.49^{* *}$ & $\begin{array}{l}839.67 \pm 33.17^{*} \\
*\end{array}$ & $\begin{array}{l}519.00 \pm 103.33^{*} \\
*\end{array}$ \\
\hline \multicolumn{6}{|c|}{ With S9 metabolic activation } \\
\hline Solvent 1 & $111.00 \pm 2.65$ & $36.67 \pm 4.62$ & $169.33 \pm 31.79$ & $278.00 \pm 6.93$ & $23.00 \pm 12.12$ \\
\hline Solvent 2 & $117.33 \pm 2.08$ & $39.33 \pm 3.51$ & $155.33 \pm 25.01$ & $270.67 \pm 10.60$ & $13.33 \pm 2.89$ \\
\hline
\end{tabular}


Safety Evaluation of Seal Oil and its Lipid-Lowering Effect on Hypercholesterolemia Rats

\begin{tabular}{|c|c|c|c|c|c|}
\hline Untreated & $123.00 \pm 12.29$ & $35.67 \pm 1.53$ & $177.00 \pm 29.60$ & $267.33 \pm 2.31$ & $18.00 \pm 7.21$ \\
\hline \multicolumn{6}{|l|}{ Seal oil $(\mu \mathrm{g} / \mathrm{plate})$} \\
\hline 50 & $121.67 \pm 9.02$ & $37.67 \pm 2.89$ & $191.67 \pm 5.51$ & $277.33 \pm 14.01$ & $24.00 \pm 3.61$ \\
\hline 158 & $123.33 \pm 12.86$ & $33.33 \pm 4.93$ & $155.00 \pm 31.48$ & $264.67 \pm 7.02$ & $23.67 \pm 8.39$ \\
\hline 500 & $121.67 \pm 12.50$ & $37.33 \pm 6.43$ & $189.67 \pm 9.24$ & $279.00 \pm 21.66$ & $17.67 \pm 5.86$ \\
\hline 1580 & $129.00 \pm 4.00$ & $36.67 \pm 2.89$ & $133.00 \pm 6.56$ & $286.00 \pm 8.89$ & $32.00 \pm 2.00$ \\
\hline 5000 & $123.00 \pm 6.00$ & $35.33 \pm 4.16$ & $163.33 \pm 24.66$ & $276.67 \pm 17.47$ & $27.00 \pm 7.81$ \\
\hline Positive control 2 & $\begin{array}{l}1448.00 \pm 74.51^{*} \\
*\end{array}$ & $\begin{array}{l}2043.00 \pm 111.95^{*} \\
*\end{array}$ & $\begin{array}{l}964.33 \pm 45.06^{*} \\
*\end{array}$ & $\begin{array}{l}795.33 \pm 75.16^{*} \\
*\end{array}$ & $498.67 \pm 22.03^{* *}$ \\
\hline
\end{tabular}

Values are expressed as the means $\pm S D(n=10) .{ }^{*} P<0.05$ Compared with Solvent significant difference, ${ }^{* *} P<0.01$ Compared with Solvent very significant difference

Solvent1: sterile water; Solvent 2: DMSO.

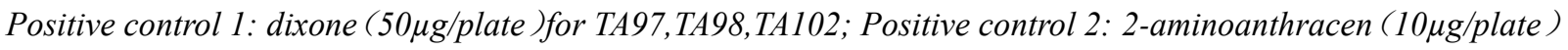

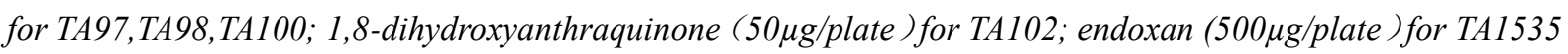

\subsubsection{In Vivo Mouse Bone Marrow Micronucleus Test}

As shown in Table 4, seal oil had no significant inhibitory effect on the proliferation of bone marrow cells of mice of two genders, and the PCE/RBC ratios of three dose groups indicated that it has no cytotoxicity. There was no significant difference in the micronucleus rate of bone marrow polychromatic erythrocytes between the two sex mice and the solvent group $(P>0.05)$. The micronucleus rate of bone marrow polychromatic erythrocytes in the positive group was significantly higher than that in the solvent group $(P<0.01)$, indicating that the tested animals were sensitive and reliable. The results indicated that seal oil was not cytotoxic to bone marrow through oral exposure and mutagenic to somatic chromosomes in mice.

Table4. Results of in vivo mice bone marrow micronucleus test for seal oil

\begin{tabular}{|c|c|c|c|c|c|c|c|}
\hline \multirow[b]{2}{*}{$\begin{array}{c}\text { Does } \\
(\mathrm{g} / \mathrm{kg} \mathrm{BW})\end{array}$} & \multirow[b]{2}{*}{$\begin{array}{c}\text { Number } \\
\text { of } \\
\text { animals }\end{array}$} & \multicolumn{3}{|c|}{ PCE } & \multicolumn{3}{|c|}{ Micronucleus } \\
\hline & & $\begin{array}{c}\text { Number of PCE } \\
\text { observed per } \\
\text { animal }\end{array}$ & $\begin{array}{c}\text { Number of } \\
\text { RBC observed } \\
\text { per animal }\end{array}$ & $\mathrm{PCE} / \mathrm{RBC}$ & $\begin{array}{c}\text { Number of } \\
\text { PCE }\end{array}$ & $\begin{array}{c}\text { Number of } \\
\text { MNPCE }\end{array}$ & $\begin{array}{l}\text { Micronucleus } \\
\text { frequency }(\% 0)\end{array}$ \\
\hline \multicolumn{8}{|l|}{ female } \\
\hline Positive & 5 & $100.40 \pm 7.00$ & 200 & $0.50 \pm 0.04$ & $5 \times 2000$ & 116 & $11.60 \pm 1.50^{\# \#}$ \\
\hline 0.95 & 5 & $95.60 \pm 12.30$ & 200 & $0.48 \pm 0.06$ & $5 \times 2000$ & 30 & $3.00 \pm 0.60$ \\
\hline 1.90 & 5 & $95.00 \pm 4.60$ & 200 & $0.48 \pm 0.02$ & $5 \times 2000$ & 29 & $2.90 \pm 0.40$ \\
\hline Solvent & 5 & $100.40 \pm 9.70$ & 200 & $0.50 \pm 0.05$ & $5 \times 2000$ & 32 & $3.20 \pm 0.60$ \\
\hline Positive & 5 & $99.00 \pm 7.10$ & 200 & $0.50 \pm 0.04$ & $5 \times 2000$ & 120 & $12.00 \pm 1.00^{\# \#}$ \\
\hline 0.95 & 5 & $97.40 \pm 7.20$ & 200 & $0.49 \pm 0.04$ & $5 \times 2000$ & 30 & $3.00 \pm 0.40$ \\
\hline 1.90 & 5 & $103.00 \pm 7.60$ & 200 & $0.52 \pm 0.04$ & $5 \times 2000$ & 32 & $3.20 \pm 0.30$ \\
\hline 3.80 & 5 & $98.40 \pm 10.50$ & 200 & $0.49 \pm 0.05$ & $5 \times 2000$ & 31 & $3.10 \pm 0.40$ \\
\hline
\end{tabular}

Values are expressed as the means $\pm S D(n=10)$.

Solvent1: sterile water; Solvent 2: DMSO; ${ }^{\# P<0.05, ~ c o m p a r e d ~ w i t h ~ t h e ~ s o l v e n t ~ s i g n i f i c a n t ~ d i f f e r e n c e ; ~}{ }^{\#} P<0.01$, 
compared with the solvent very significant difference.

\subsubsection{Spermatocyte Chromosomal Aberration Test in Mice.}

As shown in Table 5, there was no significant difference in spermatocyte aberration rate and chromosome aberration rate between seal oil dose group and solvent group $(P>0.05)$. However, the rate of abnormal spermatocytes and the rate of chromosome aberration in the positive group were significantly higher than those in the solvent group $(P<0.05)$.

Table5. The results show spermatocyte chromosomal aberrations

\begin{tabular}{|c|c|c|c|c|c|c|c|c|}
\hline \multirow{2}{*}{$\begin{array}{l}\text { Does }(\mathrm{g} / \\
\mathrm{kg} \mathrm{BW})\end{array}$} & \multirow{2}{*}{$\begin{array}{l}\text { No. of } \\
\text { cells }\end{array}$} & \multicolumn{3}{|c|}{$\begin{array}{c}\text { Types of chromosomal } \\
\text { dysgenesis }\end{array}$} & \multirow{2}{*}{$\begin{array}{l}\text { Chromoso } \\
\text { mal } \\
\text { abnormal } \\
\text { ity }\end{array}$} & \multirow{2}{*}{$\begin{array}{c}\text { Chromosomal } \\
\text { abnormality } \\
(\%)\end{array}$} & \multirow{2}{*}{$\begin{array}{c}\text { Abnor } \\
\text { mal } \\
\text { cells }\end{array}$} & \multirow{2}{*}{$\begin{array}{c}\text { Abnor } \\
\text { mal } \\
\text { cells } \\
(\%)\end{array}$} \\
\hline & & $\begin{array}{c}\text { Fragm } \\
\text { ent }\end{array}$ & $\begin{array}{c}\text { Micro } \\
\text { chromoso } \\
\text { me }\end{array}$ & $\begin{array}{c}\text { Translocat } \\
\text { ion }\end{array}$ & & & & \\
\hline Solvent & 500 & 2 & 0 & 0 & 2 & 0.4 & 2 & 0.4 \\
\hline Positive & 500 & 16 & 2 & 0 & 18 & $3.6^{\#}$ & 17 & $3.6^{\#}$ \\
\hline 0.95 & 500 & 2 & 0 & 0 & 2 & 0.4 & 2 & 0.4 \\
\hline 1.90 & 500 & 1 & 0 & 0 & 1 & 0.2 & 1 & 0.2 \\
\hline 3.80 & 500 & 1 & 0 & 0 & 1 & 0.2 & 1 & 0.2 \\
\hline
\end{tabular}

Solvent: sterile water; Positive: endoxan. ${ }^{\sharp} P<0.05$, compared with the solvent significant difference

\subsection{Seal Oil Lipid-Lowering in Hypercholesterolemia Rats Study}

\subsubsection{Effect of seal oil on the body weight of hypercholesterolemia rats}

As shown in Figure 4 (A), the Control were given normal feed and the Model were given high cholesterol feed. After 2 weeks of modeling, there was no significant difference in body weight between the groups. As shown in Figure 5 (A), compared with the Control, the weight of the Model did not increase significantly $(P>0.05)$ after the 6th week. Although the body weight of the seal oil dose group increased compared with the Model, the data was not statistically significant and the difference was not significant $(P>0.05)$.

(A)

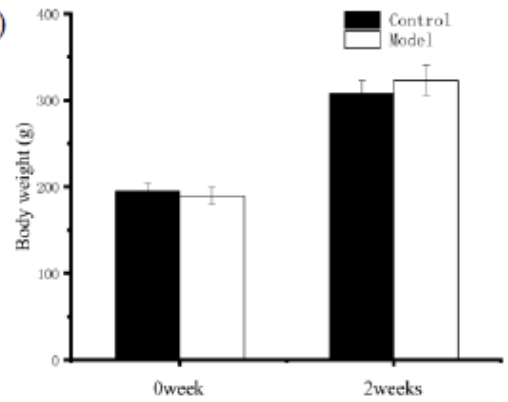

(B)

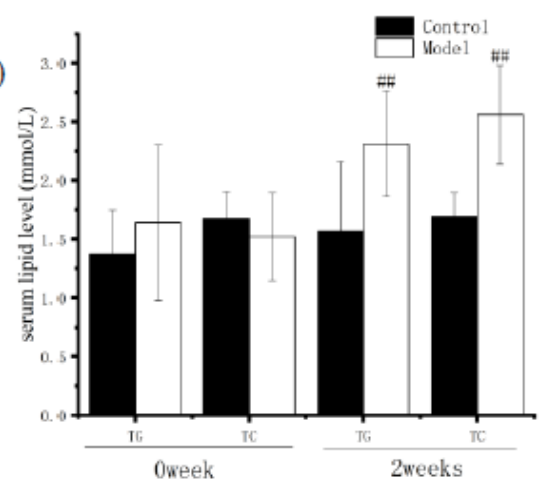

Figure 4. Body weight(A) and serum lipid level (B) at 0 week and 2 weeks. ( ${ }^{*} P<0.05$ : Compared with control group significant difference, ${ }^{\#} P<0.01$ : Compared with control group very significant difference) 
(A)

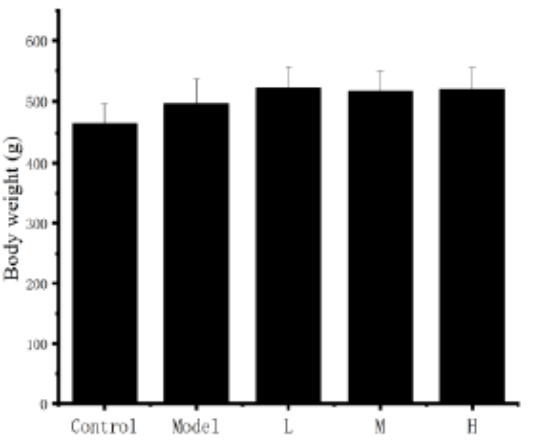

(B)

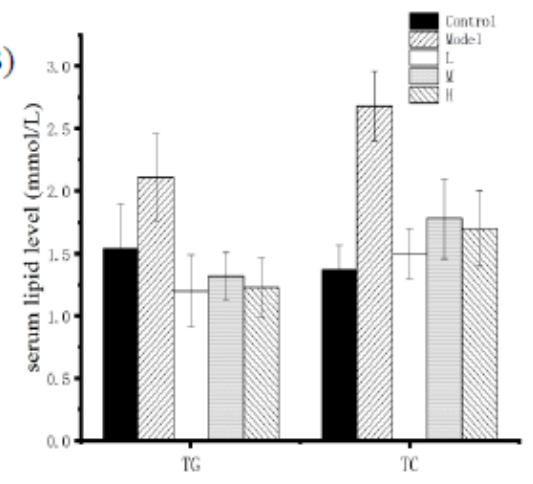

Figure 5. Effect of seal oil on body weight (A) and serum lipid level (B) in hypercholesterolemia rats $\left({ }^{\#} P<0.05\right.$ : Compared with control group significant difference, ${ }^{\#} P<0.01$ : Compared with control group very significant difference, ${ }^{*} P<0.05$ : Compared with model group significant difference, ${ }^{* *} P<0.01$ : Compared with model group very significant difference)

\subsubsection{Effect of Seal Oil on Serum Lipid in Hypercholesterolemia Rat}

As shown in Figure 4(B), the Control were given normal feed, and the Model were given high cholesterol feed for modeling with 2 weeks. Compared with the Control, the Model had a very significant increase in serum TC $(\mathbf{P}<0.01)$, while serum TG was also very significant $(P<0.01)$, indicating the animal type with hypercholesterolemia was established. After grouping in the 3rd week, each dose group was given seal oil. After the end of the 6th week, compared with the Model, serum TC and TG in serum of the $\mathrm{L}, \mathrm{M}$ and $\mathrm{H}$ were very significantly reduced $(P<0.01)$. These results indicate that seal oil can reduce effectively serum TC and TG in hypercholesterolemia rats.

\section{DISCUSSION}

To inhibit the development of thrombus, Seal oil can effectively regulate blood lipids(1) and reduce blood lipid levels in hyperlipidemia(21). And it can reduce joint pain in patients with inflammatory bowel disease(22). Eilertsen et al. used apoE-/- mice to establish an atherosclerosis model and found that Seal oil has anti-atherosclerotic function (23). Wang et al. found that the use of seal oil may be beneficial in the treatment of breast cancer (24). Khol-Parisini et al. found that seal oil has anti-inflammatory activity(25). The role of seal oil is also reflected in healthy, normal cholesterol subjects. The supplementation of seal oil reduces the n-6/n-3 ratio, increases EPA, DHA, and DPA, as well as serum phospholipids and non-esterified fatty acid (NEFA). The ratio of DHA/Arachidonic acid, while showing a moderate beneficial effect on fibrinogen(26). Therefore, it is more necessary to evaluate the safety of seal oil. Such the test is very important.

In order to evaluate the safety of seal oil, this article has done the acute oral toxicity study, subacute oral toxicity and genotoxicity studies of seal oil. The result of acute toxicity study demonstrated that the LD50 of seal oil in mice was greater than $19.00 \mathrm{~g} / \mathrm{kg}$ BW and there was no abnormality in the main organs of the mice during the experiment. The results of the subacute oral toxicity study showed that there was no abnormal change in the behavior of the rats, and there were no significant differences in the weight, blood indexes, biochemical indexes and organ coefficients of the rats $(P>0.05)$. It shows that seal oil has no obvious effect on rats.

The genotoxicity studies includes three experiments, Ames test, mouse bone marrow micronucleus assay and mice sperm abnormality assay. In Ames test, all dosage groups of seal oil had no obvious mutagenic effect on Salmonella typhimurium (TA97, TA98, TA100, TA102, TA1535) with or without S9, and there was no significant difference compared with the solvent group. The results of reverse mutation test of Salmonella typhimurium were negative with or without S9 system in seal oil. The 
Ames test is specifically designed to detect that it may lead to an assessment of the mutagenic potential of bacteria and to estimate the carcinogenic potential of environmental mixtures(27). Mouse bone marrow micronucleus test was conducted in male and female mice. The three dose groups of seal oil mouse bone marrow polychromatic erythrocyte micronucleus rate were not significant compared with the solvent group. The difference has no significant effect on the PCE/RBC ratio. Mouse bone marrow micronucleus test can detect chemically induced chromosome damage, as well as chromosome loss and breakage(28). In the mice sperm abnormality test, seal oil dose group chromosome aberrations (fragments, microsomes, translocateions), chromosome cell aberration rate was not significant compared with the solvent group difference. The above experiments show that seal oil have no genetic toxicity.

In the experiment of hypercholesterolemia rats, each dosage group of seal oil can reduce cholesterol and triglycerides in hypercholesterolemia rats, the difference is very significant $(P<0.01)$. It shows that seal oil can not only reduce the serum lipid level of hyperlipidemia rats, but also has an effective lipid-lowering effect on hypercholesterolemia rats.

\section{CONCLUSION}

In summary, acute oral toxicity, subacute oral toxicity and genetic toxicity research of negative results, as well as the negative results of genetic toxicity research of seal oil. Seal oil has the active function of the hypercholesterolemia rats lowering of serum lipid. The results of studies support the product used for the safety of the food consumption of human potential and lipid-lowering effect, either in the form of food or dietary supplements.

\section{ACKNOWLEDGMENTS}

This research was funded by Wuxianji Co., Ltd. (Guangdong, China). The authors are grateful to the facilities of Beijing Key Laboratory of Bioactive Substances and Functional Food.

\section{REFERENCES}

[1] Mann, N. J., O'Connell, S. L., Baldwin, K. M., Singh, I., and Meyer, B. J., Effects of seal oil and tuna-fish oil on platelet parameters and plasma lipid levels in healthy subjects, Lipids, 45, 669 (2010).

[2] O'Keefe, E. L., Harris, W. S., DiNicolantonio, J. J., Elagizi, A., Milani, R. V., Lavie, C. J., and O'Keefe, J. H., Sea Change for Marine Omega-3s: Randomized Trials Show Fish Oil Reduces Cardiovascular Events, Mayo Clin Proc, 94, 2524 (2019).

[3] Dubey, P., Jayasooriya, A. P., and Cheema, S. K., Diets Enriched in Fish-Oil or Seal-Oil have Distinct Effects on Lipid Levels and Peroxidation in BioF1B Hamsters, Nutr Metab Insights, 4, 7 (2011).

[4] Christensen, M. S., and Hoy, C. E., Effects of dietary triacylglycerol structure on triacylglycerols of resultant chylomicrons from fish oil- and seal oil-fed rats, Lipids, 31, 341 (1996).

[5] Ailhaud, G., Massiera, F., Weill, P., Legrand, P., Alessandri, J. M., and Guesnet, P., Temporal changes in dietary fats: role of $\mathrm{n}-6$ polyunsaturated fatty acids in excessive adipose tissue development and relationship to obesity, Prog Lipid Res, 45, 203 (2006).

[6] Liu, G., Gibson, R. A., Callahan, D., Guo, X. F., Li, D., and Sinclair, A. J., Pure omega 3 polyunsaturated fatty acids (EPA, DPA or DHA) are associated with increased plasma levels of 3-carboxy-4-methyl-5-propyl-2-furanpropanoic acid (CMPF) in a short-term study in women, Food Funct, 11, $2058(2020)$.

[7] Guo, X. F., Sinclair, A. J., Kaur, G., and Li, D., Differential effects of EPA, DPA and DHA on cardio-metabolic risk factors in high-fat diet fed mice, Prostaglandins Leukot Essent Fatty Acids, 136, 47 (2018). 
[8] Stupin, A., Mihalj, M., Kolobaric, N., Susnjara, P., Kolar, L., Mihaljevic, Z., Matic, A., Stupin, M., Jukic, I., Kralik, Z., Grcevic, M., Kralik, G., Seric, V., and Drenjancevic, I., Anti-Inflammatory Potential of n-3 Polyunsaturated Fatty Acids Enriched Hen Eggs Consumption in Improving Microvascular Endothelial Function of Healthy Individuals-Clinical Trial, Int J Mol Sci, 21 (2020).

[9] Hogenkamp, A., Ehlers, A., Garssen, J., and Willemsen, L. E. M., Allergy Modulation by N-3 Long Chain Polyunsaturated Fatty Acids and Fat Soluble Nutrients of the Mediterranean Diet, Front Pharmacol, 11, 1244 (2020).

[10] Joffre, C., Dinel, A. L., Chataigner, M., Pallet, V., and Laye, S., n-3 Polyunsaturated Fatty Acids and Their Derivates Reduce Neuroinflammation during Aging, Nutrients, 12 (2020).

[11] Eltweri, A. M., Thomas, A. L., Metcalfe, M., Calder, P. C., Dennison, A. R., and Bowrey, D. J., Potential applications of fish oils rich in omega-3 polyunsaturated fatty acids in the management of gastrointestinal cancer, Clin Nutr, 36, 65 (2017).

[12] Bae, J. S., Oh, A. R., and Cha, J. Y., Regulation of Cholesterol Metabolism in Liver: Link to NAFLD and Impact of n-3 PUFAs, J Lifestyle Med, 3, 19 (2013).

[13] Broadwater, M. H., Seaborn, G. T., and Schwacke, J. H., Forensic Identification of Seal Oils Using Lipid Profiles and Statistical Models, J Forensic Sci, 58, 336 (2013).

[14] Chong, A. J., Lim, S. W., Lee, Y. L., Chio, C. C., Chang, C. H., Kuo, J. R., and Wang, C. C., The Neuroprotective Effects of Simvastatin on High Cholesterol Following Traumatic Brain Injury in Rats, World Neurosurg, 132, e99 (2019).

[15] Goritz, C., Mauch, D. H., and Pfrieger, F. W., Multiple mechanisms mediate cholesterol-induced synaptogenesis in a CNS neuron, Mol Cell Neurosci, 29, 190 (2005).

[16] Huang, X., Tang, J., Zhou, Q., Lu, H., Wu, Y., and Wu, W., Polysaccharide from fuzi (FPS) prevents hypercholesterolemia in rats, Lipids Health Dis, 9, 9 (2010).

[17] Choi, M., Ju, J., Suh, J. S., Park, K. Y., and Kim, K. H., Effects of Omega-3-Rich Harp Seal Oil on the Production of Pro-Inflammatory Cytokines in Mouse Peritoneal Macrophages, Prev Nutr Food Sci, 20, 83 (2015).

[18] Venil, C. K., Khasim, A. R., Aruldass, C. A., and Ahmad, W. A., Safety evaluation of flexirubin from Chryseobacterium artocarpi CECT 8497: Acute, sub-acute toxicity and mutagenicity studies, Process Saf Environ, 112, 362 (2017).

[19] Lagarto, A., Bueno, V., Perez, M. R., Rodriguez, C. C., Guevara, I., Valdes, O., Bellma, A., Gabilondo, T., and Padron, A. S., Safety evaluation of the venom from scorpion Rhopalurus junceus: Assessment of oral short term, subchronic toxicity and teratogenic effect, Toxicon, 176, 59 (2020).

[20] Nakajima, A., Nemoto, K., and Ohizumi, Y., An evaluation of the genotoxicity and subchronic toxicity of the peel extract of Ponkan cultivar 'Ohta ponkan' (Citrus reticulata Blanco) that is rich in nobiletin and tangeretin with anti-dementia activity, Regul Toxicol Pharmacol, 114, 104670 (2020).

[21] Meyer, B. J., Lane, A. E., and Mann, N. J., Comparison of seal oil to tuna oil on plasma lipid levels and blood pressure in hypertriglyceridaemic subjects, Lipids, 44, 827 (2009).

[22] Gregersen, K., Lind, R. A., Valeur, J., Bjorkkjaer, T., Berstad, A., and Lied, G. A., Duodenal administered seal oil for patients with subjective food hypersensitivity: an explorative open pilot study, Int J Gen Med, 3, 383 (2010).

[23] Eilertsen, K. E., Maehre, H. K., Cludts, K., Olsen, J. O., and Hoylaerts, M. F., Dietary enrichment of apolipoprotein E-deficient mice with extra virgin olive oil in combination with seal oil inhibits atherogenesis, Lipids Health Dis, 10, 41 (2011). 
[24] Wang, Z., Butt, K., Wang, L., and Liu, H., The effect of seal oil on paclitaxel induced cytotoxicity and apoptosis in breast carcinoma MCF-7 and MDA-MB-231 cell lines, Nutr Cancer, 58, 230 (2007).

[25] Khol-Parisini, A., van den Hoven, R., Leinker, S., Hulan, H. W., and Zentek, J., Effects of feeding sunflower oil or seal blubber oil to horses with recurrent airway obstruction, Can J Vet Res, 71, 59 (2007).

[26] Conquer, J. A., Cheryk, L. A., Chan, E., Gentry, P. A., and Holub, B. J., Effect of supplementation with dietary seal oil on selected cardiovascular risk factors and hemostatic variables in healthy male subjects, Thromb Res, 96, 239 (1999).

[27] Ke, Q., Fulmer, P., and Mizutani, A., Toxicological evaluation of beta-Galactosidase enzyme produced by Papiliotrema terrestris, Regul Toxicol Pharmacol, 92, 213 (2018).

[28] Vieira, P. M., Veronezi, E., Silva, C. R., and Chen-Chen, L., Detection of genotoxic, cytotoxic, and protective activities of Eugenia dysenterica DC. (Myrtaceae) in mice, J Med Food, 15, 563 (2012).

Citation: Bo Zhang, et.al., Safety Evaluation of Seal Oil and its Lipid-Lowering Effect on Hypercholesterolemia Rats. International Journal of Research Studies in Biosciences. 2021; 9(1): 20-32. DOI: https://doi.org/10.20431/2349-0365.0901003.

Copyright: (C) 2021 Authors. This is an open-access article distributed under the terms of the Creative Commons Attribution License, which permits unrestricted use, distribution, and reproduction in any medium, provided the original author and source are credited. 